\title{
POVOS INDÍGENAS: A VIDA E O DIREITO DE ACREDITAR
}

\section{INDIGENOUS PEOPLE: LIFE AND THE RIGHT TO BELIEVE}

Resumo: Trata-se de um estudo que reflete sobre a proteção e promoção da diversidade como expressão da democracia, tolerância, justiça social e respeito mútuo e que entende que a questão social referente aos povos indígenas quanto aos seus costumes que envolvem a morte de bebês indígenas recém-nascidos, por serem gêmeos, precisa ser debatida para que se encontrem soluções respeitosas e humanitárias como a possibilidade de adoção.

Palavras-chave: Direitos Humanos. Agenda 2030 ONU. Pobreza. Povos Indígenas. Adoção.

Abstract: It is a study that reflects about the protection and promotion of diversity as an expression of democracy, tolerance, social justice and mutual respect, and understands that the social question concerning indigenous peoples as to their customs involving the death of indigenous newborn, because they are twins, needs to be debated so that discovering arespectful and humane solution, such as the possibility of adoption can be found.

\footnotetext{
i Doutoranda em Bioética, Ética Aplicada e Saúde Coletiva do Programa de Pós-Graduação em Associação da Universidade Federal do Rio de Janeiro (UFRJ), Universidade Federal Fluminense (UFF), Universidade do Estado do Rio de Janeiro (UERJ) e Fundação Oswaldo Cruz (FIOCRUZ). Mestre em Justiça Administrativa (Direito e Economia) - Mestrado Profissional, pela Universidade Federal Fluminense (UFF) e Mestre em Economia Empresarial, pela Universidade Cândido Mendes (UCAM). Pósgraduada (lato sensu) em Direito Tributário, Didática de Ensino Superior, Direito Processual Civil, pela Universidade Estácio de Sá (UNESA) bem como Pós-graduada (lato sensu) em Economia Empresarial pela Universidade Cândido Mendes (UCAM).
} 
Keywords: Human Rights. Agenda 2030 UN. Poverty. Indigenous Peoples. Adoption.

\section{INTRODUÇÃO}

O tema indígena apresentado é muito presente nos dias atuais, extremamente polêmico, que envolve a morte de bebês indígenas, recémnascidos, por serem gêmeos, de algumas tribos indígenas brasileiras, em especial, a dos "Yanomamis".

Esse dilema se explica, considerando que algumas tribos indígenas brasileiras, diante do nascimento de filhos gêmeos, por considerar que um deles é um "ser do mal", tem o costume de matar um deles, por exemplo, por apedrejamento. Como é que se tem a certeza de que o filho que morre, seria o filho certo, qual seja, o "ser do mal"? Qual o limite a ser traçado entre uma crença de um povo e a garantia fundamental do direito à vida, consagrada no Estado Democrático de Direito, sendo um de seus pilares, a dignidade da pessoa humana, conforme redação ínsita do inciso III da Carta Magna.

Impende esclarecer, por oportuno, que essa questão social envolve a luta, englobando valores fundamentais, nos quais de um lado está o direito à vida; e de outro a crença de um povo, que é consagrada em seus costumes. Nesse duelo, quem realmente perde ou quem ganha?

A Antropologia, a Biomedicina, a Bioética, o Direito, dentre outras áreas buscam soluções para uma questão que abala os pilares do Estado Democrático de Direito, na tentativa de apontar uma porta que será a saída de um Estado de sua própria caverna, em busca do mundo exterior, repleto de luz, por um desenvolvimento sustentável que começa através de políticas públicas que maximizam o valor de cada um, do povo brasileiro.

O presente estudo, por sua vez, aponta a Adoção como uma porta de saída para as mortes de crianças indígenas por motivos de crença. Ao serem observados os dados estatísticos do quadro de adoção no Brasil, verifica-se que existem menos crianças e adolescentes no País para serem adotadas do que o número de pessoas interessadas em adotar.

Desta feita, diante da realidade brasileira, a adoção deve ser a resposta para o problema apresentado no presente estudo, não podendo ser permitido que crianças continuem morrendo, diariamente, em nome da crença de um povo. 
A concepção hodierna não considera a pobreza somente no sentido de ausência de recursos financeiros para suprir as necessidades básicas do indivíduo. A pobreza deve ser conceituada também, num segundo sentido, pela ausência de capacidades. Isso porque quanto menor a capacidade da pessoa, menos chance ela tem para auferir renda. Por isso, é preciso analisar esse aspecto substancial da pobreza para que se possa erradicar a pobreza mundial.

Quando se analisam os conceitos de pobreza e riqueza, é possível concluir que para que se possa transformar o quadro de pobreza em riqueza, deve ser utilizada a ponte do desenvolvimento sustentável que prima pela vida humana com qualidade.

Nesse sentido, o bem da vida não pode ser subjugado por causa da crença de um povo. O indivíduo precisa viver e viver com qualidade, cabendo ao Governo providenciar os recursos para que ele tenha uma vida com sustentabilidade, contribuindo para o desenvolvimento sustentável do planeta.

\section{A VIDA E $O$ DIREITO DE ACREDITAR}

É mister ressaltar que o estudioso, quando está diante de um problema para ser resolvido, deve comparar esse problema a um poliedro, um dodecaedro, por exemplo, onde a figura geométrica espacial aparece com diversas vertentes. Dessa feita, foram escolhidas as áreas da Antropologia, do Direito, da ética aplicada e da Sociologia para ser analisada a questão em epígrafe, malgrado existam diversas outras, que poderiam avaliar a presente temática.

Em consonância com o relativismo cultural, inexistem valores universais que sejam capazes de se consubstanciarem em verdadeiras bússolas para a humanidade, com uma receita pré-moldada, estabelecendo os padrões do certo e errado. Simplesmente, não há um modelo que possa explicar determinada conduta social para os demais. Existe, assim, uma relativação dos valores por parte de quem os observa, em prol da tolerância cultural. Nesse segmento, as ações humanas devem ser observadas sob a lente de sua própria cultura.

Sob uma visão jurídica, vislumbra-se uma luta de forças, em que de um lado está o bem da vida e de outro, como valor, o direito de acreditar. 
É cediço que o crime de infanticídio está tipificado, no bojo do artigo 123 do Código Penal, que apregoa a seguinte redação: "Infanticídio: Art. 123 - Matar, sob a influência do estado puerperal, o próprio filho, durante o parto ou logo após" (BRASIL, 1940).

Por seu turno, impende ressaltar, por oportuno, que de acordo com a Declaração das Nações Unidas sobre os Direitos dos Povos Indígenas, está prevista a garantia da diversidade cultural e os direitos dos povos indígenas. $\mathrm{O}$ item 1 do artigo $8^{\circ}$ apregoa que "os povos e pessoas indígenas têm direito a não sofrer assimilação forçada ou a destruição de sua cultura" (ORGANIZAÇÃO DAS NAÇÕES UNIDAS PARA A EDUCAÇÃO E CIÊNCIA E A CULTURA, 2009, p. 18). Assim, também, o item 1 do artigo 12 do mesmo documento, garante a continuidade das tradições dos povos indígenas, a saber:

"Artigo 12.

1. Os povos indígenas têm o direito de manifestar, praticar, desenvolver e ensinar suas tradições, costumes e cerimônias espirituais e religiosas; de manter e proteger seus lugares religiosos e culturais e de ter acesso a estes de forma privada; de utilizar e dispor de seus objetos de culto e de obter a repatriação de seus restos humanos (ORGANIZAÇÃO DAS NAÇÕES UNIDAS PARA A EDUCAÇÃO E CIÊNCIA E A CULTURA, 2009, p. 21)."

O item 1 do artigo $7^{\circ}$ determina que "os indígenas têm direito à vida, à integridade física e mental, à liberdade e à segurança pessoal". Nesse sentido, a aludida Declaração garante a proteção do direito da criança indígena, devendo o Estado adotar medidas, junto aos povos indígenas, para assegurar esses direitos, conforme se observa adiante:

"Artigo 22.

1. Particular atenção será prestada aos direitos e às necessidades especiais de idosos, mulheres, jovens, crianças e portadores de deficiência indígenas na aplicação da presente declaração.

2. Os Estados adotarão medidas, junto com os povos indígenas, para assegurar que as mulheres e as crianças indígenas desfrutem de proteção e de garantias plenas contra todas as formas de violência e de discriminação. (ORGANIZAÇÃ̃O DAS NAÇÕES UNIDAS PARA A EDUCAÇÃO E ClÊNCIA E A CULTURA, 2009, p.p. 28-29)." 
Deve ser ressaltado, que a UNESCO, ao promulgar a Declaração garantista do Direito dos Povos Indígenas, também, através do artigo 34, limita esses direitos aos parâmetros dos direitos humanos internacionais, conforme texto infracitado:

\begin{abstract}
"Artigo 34. Os povos indígenas têm o direito de promover, desenvolver e manter suas estruturas institucionais e seus próprios costumes, espiritualidade, tradições, procedimentos, práticas e, quando existam costumes ou sistema jurídicos, em conformidade com as normas internacionais de direitos humanos. (grifos nossos). (ORGANIZAÇÃO DAS NAÇÕES UNIDAS PARA A EDUCAÇÃO E CIÊNCIA E A CULTURA, 2009, p. 39)."
\end{abstract}

A mesma Declaração enfatiza que os direitos indígenas previstos e assegurados, no bojo do seu texto, constituem-se em normas mínimas da sobrevivência desses povos: "Artigo 43. Os direitos reconhecidos na presente Declaração constituem as normas mínimas para a sobrevivência, a dignidade e o bem-estar dos povos indígenas do mundo." Nesse diapasão, a Declaração da Diversidade Cultural e Direitos Humanos, da UNES$\mathrm{CO}$, consagra de forma literal, a supremacia e prevalência dos direitos humanos garantidos pelo Direito Internacional, em relação à diversidade cultural, no bojo do seu artigo $4^{\circ}$, intratranscrito:

"Artigo $4^{\circ}$. Os direitos humanos, garantias da diversidade cultural. A defesa da diversidade cultural é um imperativo ético, inseparável do respeito à dignidade humana. Ela implica o compromisso de respeitar os direitos humanos e as liberdades fundamentais, em particular os direitos das pessoas que pertencem a minorias e os dos povos autóctones. Ninguém pode invocar a diversidade cultural para violar os direitos humanos garantidos pelo direito internacional, nem para limitar seu alcance (ORGANIZAÇÃO DAS NAÇÕES UNIDAS PARA A EDUCAÇÃO E CIÊNCIA E A CULTURA, 2002, p. 3)."

A UNESCO, através da Declaração sobre as Responsabilidades das Gerações Presentes em Relação às Gerações Futuras, adotada em 12 de novembro de 1997, assegura, no artigo $3^{\circ}$, a manutenção e a perpetuação da Humanidade, com o devido respeito pela dignidade da pessoa humana, o que se depreende, a seguir: 


\begin{abstract}
"Artigo 3. Manutenção e perpetuação da humanidade As gerações presentes devem esforçar-se para assegurar a manutenção e a perpetuação da humanidade, com o devido respeito pela dignidade da pessoa humana. Consequentemente, a natureza e a forma da vida humana nunca devem ser prejudicadas, sob qualquer aspecto (ORGANIZAÇÃO DAS NAÇÕES UNIDAS PARA A EDUCAÇÃO E CIÊNCIA E A CULTURA, 1997, p. 4)."
\end{abstract}

Nesse giro, verifica-se que a UNESCO procurou garantir o direito indígena ao acesso à informação, nos termos do item 1 do artigo 16: "Os povos indígenas têm o direito de estabelecer seus próprios meios de informação, em seus próprios idiomas, e de ter acesso a todos os demais meios de informação não indígenas, sem qualquer discriminação."

A tutela do direito indígena, como direito das minorias também está prevista no item 2 do artigo $4^{\circ}$ da Declaração sobre os Direitos das Pessoas pertencentes a Minorias Nacionais ou Étnicas, Religiosas e Linguísticas. Elaborada pela Organização das Nações Unidas (ONU), in verbis: Artigo $4^{\circ}$.

\begin{abstract}
"Artigo 4\%.
2. Os Estados adotarão medidas para criar condições favoráveis a fim de que as pessoas pertencentes a minorias possam expressar suas características e desenvolver a sua cultura, idioma, religião, tradições e costumes, salvo em casos em que determinadas práticas violem a legislação nacional e sejam contrárias às normas internacionais (ONU, 1995, grifo nosso)."
\end{abstract}

O direito à tolerância foi consagrado na Declaração de Princípios sobre a Tolerância, pela UNESCO, que no item 1.1 do artigo $1^{\circ}$, apresentou o significado da tolerância, in verbis: Artigo $1^{\circ}$. Significado da tolerância 


\begin{abstract}
"1.1. A tolerância é o respeito, a aceitação e o apreço da riqueza e da diversidade das culturas de nosso mundo, de nossos modos de expressão e de nossas maneiras de exprimir nossa qualidade de seres humanos. É fomentada pelo conhecimento, a abertura de espírito, a comunicação e a liberdade de pensamento, de consciência e de crença. A tolerância é a harmonia na diferença. Não só é um dever de ordem ética; é igualmente uma necessidade política e jurídica. A tolerância é uma virtude que torna a paz possível e contribui para substituir uma cultura de guerra por uma cultura de paz (ORGANIZAÇÃO DAS NAÇÕES UNIDAS PARA A EDUCAÇÃO E CIÊNCIA E A CULTURA, 1997, p. 11)."
\end{abstract}

E ainda, $\mathrm{O}$ artigo $1^{\circ}$ da Declaração sobre a Raça e os Preconceitos Raciais, aprovada e proclamada pela Conferência Geral da UNESCO, em 27 de novembro de 1978, equipara todas as pessoas, em homenagem ao princípio da dignidade humana, pelo que se compreende adiante:
"Artigo $1^{\circ}$.
$\S 1$. Todos os seres humanos pertencem à mesma espécie e têm a mesma origem. Nascem iguais em dignidade e direitos e todos formam parte integrante da humanidade. $\S 2$. Todos os indivíduos e os grupos têm o direito de serem diferentes, a se considerar e serem considerados como tais. Sem embargo, a diversidade das formas de vida e o direito à diferença não podem em nenhum caso servir de pretexto aos preconceitos raciais; não podem legitimar nem um direito nem uma ação ou prática discriminatória, ou ainda não podem fundar a política do apartheid que constitui a mais extrema forma do racismo (ORGANIZA- ÇÃO DAS NAÇÕES UNIDAS PARA A EDUCAÇÃO E CIÊNCIA E A CULTURA, 1978)."

A Convenção sobre a Proteção e Promoção da Diversidade das Expressões Culturais, aprovada pela UNESCO, em Paris, de 3 a 21 de outubro de 2005, legitima a diversidade cultural como expressão da democracia, tolerância, justiça social e mútuo respeito.

Por seu turno, dentre os princípios diretores eleitos pela Convenção em comento deve ser ressaltado o princípio do respeito aos direitos humanos e às liberdades fundamentais, ínsito no bojo da redação do item 1 do artigo $2^{\circ}$, vedando, expressamente, a alegação do teor da Convenção sobre a Diversidade Cultural, em desrespeito aos direitos humanos, pelo que se observa, a seguir: 
O texto prevê que as crianças que se enquadrarem nos abusos por ela condenados, será encaminhada para a adoção. Por seu turno, convém analisar a situação da adoção no Brasil, que em consonância com os dados estatísticos apurados pelo Conselho Nacional de Justiça (CNJ), através do Cadastro Nacional de Adoção (CNA), demonstra que, de um total de crianças/adolescentes cadastradas de 9.028 , o que equivale a $100 \%$ do quantitativo, 28 são da raça indígena, distribuídos assim: 2 são da Região Norte; 1 da Região Nordeste; 17 da Região Centro-Oeste; 1 da Região Sudeste e 7 da Região Sul, conforme dados, infracitados:

\section{Tabela 1 - Cadastro nacional de adoção}

DADOS DE CRIANÇAS/ADOLESCENTES CADASTRADAS

\begin{tabular}{|c|c|c|}
\hline \multicolumn{3}{|c|}{ CADASTRO NACIONAL DE ADOÇÃO (CNA) } \\
\hline TÍTULO & TOTAL & PORCENTAGEM \\
\hline $\begin{array}{l}\text { TOTAL DE CRIANÇAS/ADOLESCENTES } \\
\text { CADASTRADAS }\end{array}$ & 9.028 & $100 \%$ \\
\hline $\begin{array}{l}\text { TOTAL DE CRIANÇAS/ADOLESCENTES DA } \\
\text { RAÇA INDIGENA }\end{array}$ & 28 & $0,31 \%$ \\
\hline $\begin{array}{l}\text { TOTAL DE CRIANÇAS/ADOLESCENTES DA } \\
\text { REGIÃO NORTE, QUE SÃO INDIGENAS }\end{array}$ & 2 & $0,53 \%$ \\
\hline $\begin{array}{l}\text { TOTAL DE CRIANÇAS/ADOLESCENTES DA } \\
\text { REGIÃO NORDESTE, QUE SÃO INDIGENAS }\end{array}$ & 1 & $0,08 \%$ \\
\hline $\begin{array}{l}\text { TOTAL DE CRIANÇAS/ADOLESCENTES } \\
\text { DA REGIÃO CENTRO-OESTE, QUE SÃO } \\
\text { INDIGENAS }\end{array}$ & 17 & $2,07 \%$ \\
\hline $\begin{array}{l}\text { TOTAL DE CRIANÇAS/ADOLESCENTES DA } \\
\text { REGIÃO SUDESTE, QUE SÃO INDIGENAS }\end{array}$ & 1 & $0,03 \%$ \\
\hline $\begin{array}{l}\text { TOTAL DE CRIANÇAS/ADOLESCENTES DA } \\
\text { REGIÃO SUL, QUE SÃO INDIGENAS }\end{array}$ & 7 & $026 \%$ \\
\hline
\end{tabular}

Fonte: Cadastro Nacional de Adoção do Conselho Nacional de Justiça (CNJ) ${ }^{1}$

Quanto ao prisma de pretendentes cadastrados, existe um total de 44.222 , equivalente a $100 \%$; sendo que $25 \%$, desse total, somente aceitam crianças da raça indígena, equivalente a 0,06\%, conforme tabela adiante:

1 Disponível em: <http://www.cnj.jus.br/cnanovo/pages/publico/index.jsf>. Acesso em: 10 ago. 2018. 


\section{Tabela 2- Cadastro nacional de adoção}

\section{DADOS DOS PRETENDENTES CADASTRADOS}

\begin{tabular}{|c|c|c|}
\hline \multicolumn{3}{|c|}{ CADASTRO NACIONAL DE ADOÇÃO (CNA) } \\
\hline TÍTULO & TOTAL & PORCENTAGEM \\
\hline $\begin{array}{l}\text { TOTAL DE PRETENDENTES CADASTRA- } \\
\text { DOS: }\end{array}$ & 44.222 & $100,00 \%$ \\
\hline $\begin{array}{l}\text { TOTAL DE PRETENDENTES QUE SOMENTE } \\
\text { ACEITAM CRIANÇAS DA RAÇA INDÍGENA: }\end{array}$ & 25 & $0.06 \%$ \\
\hline $\begin{array}{l}\text { TOTAL DE PRETENDENTES QUE ACEITAM } \\
\text { CRIANÇAS DA RAÇA INDÍGENA: }\end{array}$ & 23.313 & $52.72 \%$ \\
\hline $\begin{array}{l}\text { TOTAL DE PRETENDENTES HABILITADOS } \\
\text { NA REGIÃO NORTE }\end{array}$ & 1.567 & $100 \%$ \\
\hline $\begin{array}{l}\text { QUE ACEITAM CRIANÇAS DA RAÇA INDÍ- } \\
\text { GENA (REGIÃO NORTE): }\end{array}$ & 1.022 & $65.22 \%$ \\
\hline $\begin{array}{l}\text { TOTAL DE PRETENDENTES HABILITADOS } \\
\text { NA REGIÃO NORDESTE }\end{array}$ & 5.746 & $100 \%$ \\
\hline $\begin{array}{l}\text { QUE ACEITAM CRIANÇAS DA RAÇA INDÍ- } \\
\text { GENA (REGIÃO NORDESTE): }\end{array}$ & 3.317 & $57.73 \%$ \\
\hline $\begin{array}{l}\text { TOTAL DE PRETENDENTES HABILITADOS } \\
\text { NA REGIÃO CENTRO-OESTE }\end{array}$ & 3.322 & $100 \%$ \\
\hline $\begin{array}{l}\text { QUE ACEITAM CRIANÇAS DA RAÇA INDÍ- } \\
\text { GENA (REGIÃO CENTRO-OESTE): }\end{array}$ & 2.031 & $61.14 \%$ \\
\hline $\begin{array}{l}\text { TOTAL DE PRETENDENTES HABILITADOS } \\
\text { NA REGIÃO SUDESTE }\end{array}$ & 20.954 & $100 \%$ \\
\hline $\begin{array}{l}\text { QUE ACEITAM CRIANÇAS DA RAÇA INDÍ- } \\
\text { GENA (REGIÃO SUDESTE): }\end{array}$ & 11.143 & $53.18 \%$ \\
\hline $\begin{array}{l}\text { TOTAL DE PRETENDENTES HABILITADOS } \\
\text { NA REGIÃO SUL }\end{array}$ & 12.633 & $100 \%$ \\
\hline $\begin{array}{l}\text { QUE ACEITAM CRIANÇAS DA RAÇA INDÍ- } \\
\text { GENA (REGIÃO SUL): }\end{array}$ & 5.800 & $45.91 \%$ \\
\hline
\end{tabular}

Fonte: Cadastro Nacional de Adoção do Conselho Nacional de Justiça (CNJ)²

Cumpre ressaltar, por oportuno, que, de um total de pretendentes à adoção cadastrados de 44.222 , o que equivale a $100 \%$ do quantitativo; 
mais da metade, cerca de $52,72 \%$ aceitam crianças da raça indígena, como também a taxa de porcentagem regional oscila em torno de $50 \%$ do total de pretendentes habilitados, que aceitam crianças da raça indígena.

Nesse condão, pode ser observado ainda, que hoje, no Brasil, existe um número muito maior de pessoas, cadastradas como pretendentes à adoção, cerca de 44.222, enquanto que para serem adotadas, existem apenas 9.028 crianças/adolescentes cadastrados.

\section{CONSIDERAÇÕES FINAIS}

O Direito Internacional no último século se fortaleceu nos pilares da democracia que derrubou os muros de diversos países, com novos ordenamentos jurídicos em diversas partes do mundo. Pela razão kantiana, encontra-se uma razão abrangente da humanidade que foi reconhecida na Conferência de Viena de 1993 sobre os direitos humanos, onde o direito ao desenvolvimento se moldou como uma ferramenta essencial para a realização dos direitos humanos, quando foi reconhecida a cooperação internacional, através de uma parceria global, com o fito de equilibrar o meio ambiente econômico no plano mundial pela universalidade, interdependência e individualidade dos direitos humanos.

O direito ao desenvolvimento sustentável, à justiça social, solidariedade e cooperação internacional, dentre outros tópicos passaram a apresentar relevância no plano internacional e a ter espaço na agenda internacional, concernente às mudanças sociais e econômicas nos últimos 20 (vinte) anos, num processo de evolução.

Desta feita, o direito ao desenvolvimento sustentável se constitui como proteção estatal dos direitos humanos, tendo o seu nascedouro nos conflitos bipolares entre Leste/Oeste, na fase pós-guerra, através de um plano de economia mista com o escopo de sanar as assimetrias internacionais. Surge desse ideal o princípio do tratamento diferenciado para os países em desenvolvimento, que culminam muitas vezes em reivindicações de negociações globais.

A erradicação da pobreza urge regras internacionais mais estáveis que possam valorizar o crescimento da produtividade dos países, a valoração do homem e a sua felicidade, com políticas públicas que possam promover a saúde, a educação e o meio ambiente. 
A explicação de como a economia de um determinado país funciona é oferecida por uma teoria ou modelo econômico. Assim, o modelo econômico busca explicar fenômenos reais que envolvem as pessoas, as empresas e o Governo, de forma abstrata, buscando explicar os comportamentos através de indicadores econômicos.

É preciso microrreformas, tais como, a flexibilização do direito trabalhista, como também maior incentivo à criatividade dos trabalhadores, para que estes se condicionem às mudanças frequentes, mesmo em empresas diversas, para que sejam capazes de utilizar novos métodos de trabalho, operar novas máquinas e o que mais se ofereça. A educação deve ser prioridade nacional. É preciso um desenvolvimento sustentável que venha proteger as famílias de baixas rendas, para fins de erradicação da pobreza.

Na realidade, existe uma disparidade entre os países, em relação à Europa e aos EUA, quanto aos demais estados. Dessa feita, é preciso erradicar a pobreza pela melhoria da saúde, educação e do transporte, além do meio ambiente, dentre outros fatores.

Os instrumentos legais internacionais têm sido aprovados, no sentido de assegurar os direitos fundamentais e, sobretudo, os direitos humanos internacionais, além de proteger e promover a diversidade das expressões culturais, como forma de preservação da cultura.

Mas é preciso ressaltar que o respeito à cultura indígena não é um direito absoluto, considerando que o direito à cultura não pode se sobrepor aos direitos humanos, consagrados no plano internacional. Hoje, os povos indígenas não estão afastados por completo de outras civilizações e tem sido assegurado aos mesmos, o acesso à informação.

$O$ direito das pessoas pertencentes a minorias nacionais ou étnicas, ou religiosas ou linguísticas não pode ser contrário às normas internacionais e dessa forma, o direito à tolerância deve ser respeitado em prol da cultura de paz, em substituição a cultura de guerra, mesmo porque todas as pessoas são iguais, em homenagem ao princípio da dignidade humana.

A diversidade cultural é expressão da democracia, tolerância, justiça social e mútuo respeito, não sendo possível alegar o direito da diversidade cultural, em desrespeito aos direitos humanos e às liberdades fundamentais.

Diante do quadro de adoção no Brasil, verifica-se que existe um número deficitário de crianças ou adolescentes para suprir a demanda dos pretendentes à adoção cadastrados. 
Por outro lado, existe um projeto de lei ${ }^{3}$, que busca sanar com essa problemática de infanticídio indígena e que encaminha as crianças salvas para a adoção. Essa é a grande porta de saída para essa problemática, cabendo dentre muitas pessoas, além do profissional de saúde que se depare com essa situação da gravidez de gêmeos da indígena, que fosse utilizada a técnica da argumentação para buscar convencer as pessoas interessadas que as crianças gêmeas deveriam ser encaminhadas para a adoção.

Deve ser ressaltado, que todo esse processo de discurso argumentativo é necessário, considerando que o projeto de lei, pertinente à questão proposta, ainda se encontra em tramitação no Congresso Nacional.

Nesse diapasão-conclusivo, importa ressaltar que, ainda que não se consiga salvar todas as crianças da Tribo dos "Yanomamis", ou mesmo de qualquer outra Tribo, de sofrerem o crime de infanticídio, mas para aquela que for livre desse destino cruel, ainda que seja apenas uma criança, para essa, valeu a tentativa de reescrever a História.

\section{REFERÊNCIAS}

BRASIL. Constituição (1988). Constituição da República Federativa do Brasil de 1988. Disponível em:<http://www.planalto.gov.br/ccivil_03/ Constituicao/Constituicao.htm >. Acesso em: 07 set. 2018

BRASIL. Decreto-lei $\mathbf{n}^{\circ}$ 2.848, de 7 de dezembro de 1940. Disponível em: <http://www.planalto.gov.br/ccivil_03/decreto-lei/Del2848compilado.htm>. Acesso em: 15 ago. 2018.

ONU. Agenda 2030. Disponível em < https://nacoesunidas.org/pos2015/ agenda2030/>. Acesso em: 25/08/2018.

ONU. A Declaração sobre os direitos das pessoas pertencentes a minorias nacionais ou étnicas, religiosas e linguísticas. c1995. Disponível em: <http://www.dhnet.org.br/direitos/sip/onu/discrimina/dec92.htm>. Acesso em: 16 ago. 2018.

3 Disponível em: <http://www.camara.gov.br/proposicoesWeb/prop_mostrarintegra;jsessioni$d=B 1 A 28692$ A9835DB551DF70DB76E88E92. proposicoesWebExterno2? codteor $=459157 \&$ filena me $=P L+1057 / 2007>$. Acesso em: 30 nov. 2018. 
ONU. Declaração sobre a Raça e os Preconceitos Raciais. 1978. Disponível em: <http://www2.camara.leg.br/atividade-legislativa/comissoes/ comissoes-permanentes/cdhm/comite-brasileiro-de-direitos-humanos-e -politica-externa/DecRacPrecRac.html>. Acesso em: 16 ago. 2018.

ORGANIZAÇÃO DAS NAÇÕES UNIDAS PARA A EDUCAÇÃO E CIÊNCIA E A CULTURA. Declaração das Nações Unidas sobre os Direitos dos Povos Indígenas: perguntas e respostas. Rio de Janeiro: UNIC. Brasília: UNESCO, 2009. Disponível em: < http://unesdoc.unesco.org/images/0018/001850/185079por.pdf>. Acesso em: 13 ago. 2018.

ORGANIZAÇÃO DAS NAÇÕES UNIDAS PARA A EDUCAÇÃO E CIÊNCIA E A CULTURA. Convenção sobre a Proteção e Promoção da Diversidade das Expressões Culturais. [S.I.]: Unesco, 2005. Disponível em: <http:// unesdoc.unesco.org/images/0015/001502/150224por.pdf>. Acesso em: 16 ago. 2018.

ORGANIZAÇÃO DAS NAÇÕES UNIDAS PARA A EDUCAÇÃO E CIÊNCIA E A CULTURA. Declaração de Princípios sobre a Tolerância. São Paulo: UNESCO, 1997. Disponível em: <http://unesdoc.unesco.org/images/0013/001315/131524porb.pdf>. Acesso em: 16 ago. 2018.

ORGANIZAÇÃO DAS NAÇÕES UNIDAS PARA A EDUCAÇÃO E CIÊNCIA E A CULTURA. Declaração sobre as responsabilidades das gerações presentes em relação às gerações futuras. Brasília, DF: UNESCO, 1997. Disponível em: <http://unesdoc.unesco.org/images/0011/001108/110827por. pdf. Acesso em: 15 ago. 2018.

ORGANIZAÇÃO DAS NAÇÕES UNIDAS PARA A EDUCAÇÃO E CIÊNCIA E A CULTURA. Declaração universal sobre a diversidade cultural. [S.I.]: Unesco, 2002. Disponível em: <http://unesdoc.unesco.org/images/0012/001271/127160por.pdf>. Acesso em: 15 ago. 2018. 